\title{
Democracy Reloaded. Inside Spain's Political Laboratory from 15-M to Podemos. Cristina Flesher Fominaya. Oxford: Oxford University Press, 2020
}

\author{
Josep Lobera \\ Universidad Autónoma de Madrid \\ josep.lobera@uam.es
}

Diversas protestas sociales han tenido un papel disruptivo en la segunda década de este siglo, con formas que han puesto a prueba nuestra comprensión previa de los movimientos sociales. Algunas de ellas forjaron tipos poco convencionales de estructuras de movilización, como los llamados square movements. El último libro de Cristina Flesher Fominaya, publicado por Oxford University Press, realiza una revisión teórica amplia de lo que han supuestos estos movimientos a partir de su caso más significativo: el 15-M. Se trata de un libro ambicioso, empezando por su estructura organizada en cinco partes: democracia y 15-M; de la protesta a la ocupación; de la ocupación al movimiento; del 15-M a Podemos; y un capítulo final de conclusiones.

Esta estructura revela la intención profunda del libro: ofrecer una comprensión profunda de una concatenación de procesos sociales, en el que la movilización es una parte más de la lógica social detrás del movimiento. Flesher Fominaya ofrece, así, una visión continua de las protestas, integrando su contexto, sus precedentes, así como su cristalización en nuevas formaciones políticas. El alfa y el omega para entender que las protestas no tienen límites definitivos, ni en su inicio ni en su disolución; pero que, al mismo tiempo, contiene momentos de singularidad.

El punto de singularidad del $15-\mathrm{M}-\mathrm{y}$ quizás también su momento más definitoriofueron las acampadas. Flesher Fominaya insiste que se trata de un "evento" distinto, con una lógica interna específica. Se trataría de una "crisálida", una etapa protegida de desarrollo dentro de la cual nació el movimiento quincemayista; pero también de un crisol, un contenedor en el que se pudieron fusionar elementos antiguos y nuevos. Así, en una situación de intensidad emocional excepcional, se produjo algo nuevo: "un ethos y una cultura política más consolidados, así como nuevos conjuntos de relaciones sociales que generarían una amplia red de asambleas, colectivos, eventos y proyectos políticos interrelacionados, todos organizados en torno a una identidad colectiva y una cultura política denominada en España simplemente como 15-M" (p. 87).

En la primera parte del libro, la autora proporciona un marco teórico, analítico y empírico para comprender el surgimiento del movimiento 15-M y su desafío central a las concepciones dominantes de la democracia española. Enlazando con trabajos previos, Flesher Fominaya destaca el trabajo discursivo contrahegemónico del 15-M en torno a la comprensión de la democracia y la austeridad. La autora argumenta que la capacidad de los movimientos de proyectar narrativas contrahegemónicas es indispensable para explicar por qué tuvo lugar una contestación efectiva en España, pero no en otros países golpeados de manera similar por la crisis, como Irlanda. 
Asimismo, el libro incluye el papel de los medios y herramientas digitales en la creación de nuevas lógicas organizativas de acción colectiva, así como aspectos clave de la cultura del movimiento autónomo asambleario español que influyeron profundamente en las formas organizativas y orientaciones quincemayistas. El libro también analiza la "red 15-M" una vez finalizadas las acampadas que servían de sostén y combustible a las movilizaciones. Este análisis se centra, fundamentalmente, en tres expresiones de esa red: la PAH, el 15MpaRato y Juventud sin futuro.

Pero el libro no se detiene aquí. Flesher Fominaya aborda también el "giro electoral" del movimiento de protesta. Este abordaje es amplio y rompe con la tradicional frontera de los estudios de movimientos sociales. Ciertamente, el caso de Podemos ha suscitado una revitalización académica inusitada de la frecuentemente olvidada interrelación entre movimientos y partidos políticos (McAdam, Tarrow y Tilly, 2003); una interrelación fundamental y a la que libro de Flesher Fominaya ofrece su análisis propio.

¿Cómo consiguen los fundadores de Podemos convencer a los activistas del 15M para sumarse al giro electoral? La autora pone la mirada en el delicado paso entre movimentismo y partidismo, identificando los principales argumentos de persuasión política: la integración de la cultura política del 15-M en el partido, incluida la autonomía, el feminismo y la ética hacker. Este análisis de la dimensión persuasiva del giro electoral complementa adecuadamente otros trabajos sobre la cristalización electoral de las bases del movimiento quincemayista (e.g. Fernández-Albertos 2015; Lobera y Rogero-García 2017), así como de la naturaleza de los conflictos internos de los nuevos partidos surgidos de las protestas masivas.

Este es un punto en el que se detiene la autora: ¿Pueden ser compatibles las lógicas del movimiento y del partido? El libro explora la tensión central entre movimiento y partido analizando las críticas internas y del 15-M al partido y los desafíos que enfrenta para tratar de mantener el apoyo de su base activista de base. En esta exploración, la autora revisa las críticas a Podemos desde sus inicios, con las tensiones entre los activistas del 15-M, Izquierda Anticapitalista y la cúpula de Podemos incluso antes de conformarse como partido. También analiza en detalle la ineludible tensión producida dentro del partidos por el distanciamiento entre Îñigo Errejón y Pablo Iglesias. La autora acierta su análisis estas tensiones, dando un papel central en el conflicto entre horizontalidad y verticalidad, entre "más calle" y "más institución", una tensión que podemos considerar inherente dentro de los partidos surgidos de movimientos sociales (Lobera y Parejo, 2019).

Este ambicioso libro deja lo mejor para el capítulo de conclusiones. Tres puntos son centrales en esta última parte. La primera, que las lógicas de las redes autónomas, contra todo pronóstico, pueden construir y sostener movimientos fuertes en ausencia de estructuras organizacionales formales y profesionalizadas. La segunda conclusión matiza los análisis conectivos de la movilización (Bennett y Segerberg, 2012). Es indudable que la apropiación de las herramientas digitales por parte de los movimientos ha transformado la organización y la identidad de la acción colectiva; sin embargo, la autora muestra cómo las lógicas de acción colectiva continúan alimentando las redes autónomas en la era digital.

Finalmente, la autora evalúa el impacto y la importancia del movimiento 15-M y el potencial de los movimientos autónomos para renovar la democracia en tiempos de crisis. La autora enmarca su argumento en trabajos previos (e.g. Feenstra et al. 2017), para dar un paso más y mostrar "el papel crucial que desempeñó la praxis prefigurativa interna en la configuración del impacto del movimiento en el campo político más amplio, impactos que se entienden más comúnmente en términos de factores externos a los movimientos, en particular oportunidades políticas" (:307). Asimismo, conectando con investigaciones 
previas, Flesher Fominaya muestra convincentemente cómo las prácticas, imaginarios e identidades colectivas internas de los movimientos sociales pueden transformar simbólica y materialmente un panorama político más amplio.

\section{REFERENCIAS}

Bennett, W.L. y Segerberg A. (2012). The Logic of Connective Action. Information, Communication \& Society, 15(5): 739-68. https://doi.org/10.1080/1369118X.2012.670661

Feenstra, R., Tormey, S., Casero-Ripollés, A. y Keane, J. (2017). Refiguring Democracy: The Spanish Political Laboratory. London: Taylor and Francis.

Fernández-Albertos, J. (2015). Los votantes de Podemos. Del partido de los indignados al partido de los excluidos. Madrid: Los libros de la Catarata.

Lobera, J., y Rogero, J. (2017). Medición de la cristalización electoral de un movimiento de protesta: de la indignación al voto. Empiria: Revista de metodología de ciencias sociales, (38), 151-176. https://doi.org/10.5944/empiria.38.2018.19715

Lobera, J., y Parejo, D. (2019). Streets and Institutions? The Electoral Extension of Social Movements and Its Tensions. En R. Kinna, U. Gordon (Eds.), Routledge handbook of radical politics. New York: Taylor \& Francis.

McAdam, D., Tarrow, S. y Tilly, C. (2003). Dynamics of contention. Social Movement Studies, 2(1), 99-102. https://doi.org/10.1080/14742837.2003.10035370 